\title{
Quetiapine Induced Autoimmune Hemolytic Anemia in a Child Patient: A Case Report
}

\author{
Asiye Arıcı ${ }^{1}$, Hatice Altun ${ }^{1}$, Can Acıpayam ${ }^{2}$ \\ Departments of ${ }^{1}$ Child and Adolescent Psychiatry, ${ }^{2}$ Child Hematology and Oncology, Faculty of Medicine, Kahramanmaras Sutcu Imam \\ University, Kahramanmaras, Turkey
}

\begin{abstract}
Autoimmune hemolytic anemia is a disease characterized with destruction of erythrocytes as a result of antibody produce against patient's own erythrocytes and anemia. Autoimmune hemolytic anemia can be roughly stratified into two groups according to serological features and secondary causes including drugs induced hemolytic anemia. Drugs induced autoimmune hemolytic anemia is very rare in pediatric patients. Even though hematological side effects such as leucopenia, agranulocytosis, eosinophilia, thrombocytopenic purpura and aplastic anemia might occur due to psychotropic drug use; to the best of our knowledge there is no autoimmune hemolytic anemia case due to quetiapine, an atypical antipsychotics, in literature. We hereby describe the first child case of autoimmune hemolytic anemia during quetiapine treatment.We also are pointing out that one should keep in mind serious hematological side effects with atypical antipsychotic drug use with this case report.
\end{abstract}

KEY WORDS: Autoimmune hemolytic anemia; Antipsychotic agents; Quetiapine fumarate; Child; Hematological side effects.

\section{INTRODUCTION}

Autoimmune hemolytic anemia (AlHA) is a disease characterized with destruction of erythrocytes as a result of antibody produce against patient's own erythrocytes and anemia. AlHA can be roughly stratified into two groups according to serological features and secondary causes including drugs induced hemolytic anemia." All drugs, including psychotropic drugs, have potential to cause hemolysis and hemolysis in patients might present earlier and become fatal. ${ }^{2,3)}$

Hematological side effects of psychotropic drugs such as atypical antipsychotics are rare, but important. These hematological side effects are usually leucopenia, agranulocytosis, eosinophilia, thrombocytopenic purpura and

Received: February 21, 2017 / Revised: April 12, 2017

Accepted: April 13, 2017

Address for correspondence: Hatice Altun, MD

Department of Child and Adolescent Psychiatry, Kahramanmaras Sutcu Imam University, Faculty of Medical, Kahramanmaras, Turkey

Tel: +90-3443003374, Fax: +82-90-3443003409

E-mail: drhaticealtun@gmail.com

ORCID: https://orcid.org/0000-0002-6802-8216 aplastic anemia. Uncommonly, leukocytosis, thrombocytosis, thrombocyte function disorders and coagulopathies might occur. ${ }^{4-6)}$ Side effects of atypical antipsychotics over erythrocytes are limited. To the best of our knowledge there is no AlHA case due to atypical antipsychotics in literature.

Hereby, we report a 12-year-old boy with mental retardation (MR) and attention deficit hyperactivity disorder (ADHD) who developed AlHA with quetiapine, an atypical antipsychotic, use. Even though drug related hemoIytic anemia is rare in pediatric cases, we wanted to point out that quetiapine has such side effect and hemolysis persevered a long time even after discontinuation of the drug.

\section{CASE}

A 12-year-old male patient who has been followed-up with MR and ADHD in our clinic for 6 years was receiving risperidone for his aggression, impulsivity, insomnia and hyperactivity complaints for 5 years. Patient experienced a convulsion even though he has no history of previous neurological disease and presented to pediatric neuro-

(ㄷ) This is an Open-Access article distributed under the terms of the Creative Commons Attribution Non-Commercial License (http://creativecommons.org/licenses/by-nc/4.0) which permits unrestricted non-commercial use, distribution, and reproduction in any medium, provided the original work is properly cited. 
logical outpatient clinic. Discontinuation of risperidone was recommended because there was no other pathology except disturbance in electroencephalogram (EEG) and these EEG disturbances and convulsion were attributed to risperidone. His laboratory test results showed these results; hemoglobin $(\mathrm{Hb}) 12.4 \mathrm{~g} / \mathrm{dl}$, red blood cell (RBC) $4.42 \mathrm{M} / \mu \mathrm{l}$, white blood cell (WBC) $7.77 \mathrm{~K} / \mu \mathrm{l}$, platelet 183 $\mathrm{K} / \mu \mathrm{l}$, total bilirubin $0.7 \mathrm{mg} / \mathrm{dl}$, direct bilirubin $0.3 \mathrm{mg} / \mathrm{dl}$, indirect bilirubin $0.4 \mathrm{mg} / \mathrm{dl}$, lactate dehydrogenase (LDH) $296 \mathrm{U} / \mathrm{L}$. After discontinuation of risperidone, quetiapine $25 \mathrm{mg} /$ day was initiated for complaints of the patient. Patient's complaints of insomnia got better after changing evening dosage of quetiapine to $50 \mathrm{mg} /$ day at the 4 th day of treatment. Patient presented to pediatric emergency department with weakness and jaundice at the 8th day of treatment. In his laboratory tests these results were observed; Hb $9.6 \mathrm{~g} / \mathrm{dl}, \mathrm{RBC} 3.21 \mathrm{~m} / \mu \mathrm{l}$, reticulocyte (RET) $\% 2.01, \mathrm{WBC} 6.81 \mathrm{~K} / \mu \mathrm{l}, \mathrm{LDH} 307 \mathrm{U} / \mathrm{L}$, total bilirubin 3.8 $\mathrm{mg} / \mathrm{dl}$, direct bilirubin $0.8 \mathrm{mg} / \mathrm{dl}$, indirect bilirubin 2.88 $\mathrm{mg} / \mathrm{dl}$. In his physical examination general medical condition was moderate, his sclera was icteric and his abdomen was slightly sensitive. Patient was referred to pediatric hematology department for research of the etiology with initial diagnosis of hemolytic anemia after discontinuation of quetiapine. Patient was diagnosed as hemolytic anemia and treatment was initiated in hematology department after test results of $\mathrm{Hb} 9.6 \mathrm{~g} / \mathrm{dl}$, RBC 3.21 $\mathrm{M} / \mu \mathrm{l}, \mathrm{WBC} 6.81 \mathrm{~K} / \mu \mathrm{l}, \mathrm{LDH} 307 \mathrm{U} / \mathrm{L}, \mathrm{RET} \% 2.01$, total bilirubin $4 \mathrm{mg} / \mathrm{dl}$, direct bilirubin $0.8 \mathrm{mg} / \mathrm{dl}$, indirect bilirubin $3.2 \mathrm{mg} / \mathrm{dl}$. Patient was hydrated and metilprednisolone ( $2 \mathrm{mg} / \mathrm{kg} /$ day), nerox tablet (TB), and folbiol TB $1 \times 1$ for 3 days a week were initiated after a repeat of laboratory work-up at 4 th hour revealed these results; $\mathrm{Hb} 8.4$ $\mathrm{g} / \mathrm{dl}, \mathrm{RBC} 2.85 \mathrm{M} / \mu \mathrm{l}$, total bilirubin $3.69 \mathrm{mg} / \mathrm{dl}$, direct bilirubin $0.81 \mathrm{mg} / \mathrm{dl}$, indirect bilirubin $2.88 \mathrm{mg} / \mathrm{dl}, \mathrm{LDH}$ $278 \mathrm{U} / \mathrm{L}$, direct coombs test $(++++)$. Vitamin B12 level was normal, folic acid level was low and ferritin level was high which were $308 \mathrm{pg} / \mathrm{ml}, 3.49 \mathrm{ng} / \mathrm{ml}$, and 277.6 $\mathrm{ng} / \mathrm{ml}$, respectively. Coagulation tests, liver and kidney function tests, hepatitis parameters, human immunodeficiecy virus serology, Brucella, Salmonella, TORCH, parvovirus serology, urinalysis, chest $\mathrm{X}$-ray and abdominal $X$-ray results were normal. No glucose-6-P dehydrogenase or pyruvate kinase deficiency was present. Immunoglobulin $\mathrm{G}$ was relatively low according to his age. Immune deficiency was not considered in the patient who underwent child immunology consultation. A slight splenomegaly was identified in abdominal ultrasonography scan. His peripheral smear showed \%14 lymphocyte, $\% 86$ leukocyte with polymorphic nuclei, clustered thrombocytes and hypochromic erythrocytes and $\mathrm{Hb}$ electrophoresis was normal. Because of his direct coombs test $(++++)$ result and other laboratory and clinical findings, his AlHA diagnose was related with quetiapine use.

Even though metilprednisolone treatment was continued, his $\mathrm{Hb}$ level was $7 \mathrm{~g} / \mathrm{dl}$ at 9 th day of treatment, thus $300 \mathrm{ml}$ of erythrocyte suspension was administered and after that his $\mathrm{Hb}$ increased to $9.9 \mathrm{mg} / \mathrm{dl}$, total bilirubin was $1.7 \mathrm{mg} / \mathrm{dl}$, direct bilirubin was $0.43 \mathrm{mg} / \mathrm{dl}$ and indirect bilirubin was $1.29 \mathrm{mg} / \mathrm{dl}$. Steroid treatment of patient was reorganized to oral metilprednisolone $16 \mathrm{mg} 2 \times 2$. At $21 \mathrm{st}$ day of treatment his laboratory test results were; $\mathrm{Hb} 12.4$ $\mathrm{g} / \mathrm{dl}$, RBC $3.72 \mathrm{M} / \mu \mathrm{l}$, total bilirubin $1 \mathrm{mg} / \mathrm{dl}$, direk bilirubin $0.3 \mathrm{mg} / \mathrm{dl}$, indirect bilirubin $0.7 \mathrm{mg} / \mathrm{dl}$, direct coombs test $(+++)$ positive. Because clinical findings were improved, his treatment changed to oral metilprednisolone $16 \mathrm{mg}$ TB $2 \times 1.5$, folbiol TB $3 \times 1$ week, nerox TB $1 \times 0.5$ and discharged with a recommendation of weekly follow-up. Steroid treatment was reduced and discontinued at 145th day due to negative result of direct coombs test. At 145th day of treatment his laboratory test results were; $\mathrm{Hb} 14 \mathrm{~g} / \mathrm{dl}$, WBC $8.67 \mathrm{~K} / \mu \mathrm{l}$, total bilirubin $0.6 \mathrm{mg} / \mathrm{dl}$, direk bilirubin $0.14 \mathrm{mg} / \mathrm{dl}$, indirect bilirubin $0.46 \mathrm{mg} / \mathrm{dl}$, direct coombs test $(-)$.

\section{DISCUSSION}

Even though psychotropic drug-related hematological side effects are so rare, they shouldn't be overlooked because they might threaten the life. Most of hematological side effects caused by psychotropic drugs were explained with different pathophysiological mechanism such as bone marrow suppression, destruction of immune-associated cells, active or toxic metabolite formation and direct bone toxicity. ${ }^{4,5}$

Hematological side effects of psychotropic drugs including atypical antipsychotics effect mostly thrombocytes and leucocytes. The effects on erythrocytes are limited. In literature, there are pancytopenia cases of clozapine, quetiapine and risperidone use, while there was also a case of hemolytic uremic syndrome related with 
thrombocytopenic purpura due to quetiapine use. ${ }^{4-9)}$ However, we didn't find any atypical-antipsychotic related hemolytic anemia in our literature review.

Quetiapine, which is an atypical antipsychotic, is dibenzo thiazepine structure and has dopamine-2 (D2) receptor antagonism just like any other antipsychotic-active drug. It has a greater affinity for 5-HT2 receptors than for D2 receptors; also has an affinity for $\mathrm{H} 1$ and alpha 1 and alpha 2 adrenergic receptors. ${ }^{10)}$ Quetiapine that shows structural similarities to clozapine and olanzapine, rank 3rd in terms of hematological side effects after these two typical antipsychotics after considering case reports in the literature. There are case reports that suggest development of agranulocytosis, neutropenia and thrombocytopenic purpura due to quetiapine. ${ }^{9,11-13)}$ Our patient didn't have any abnormal clinical or laboratory test results except EEG disturbances before initiation of quetiapine treatment. Patient's hematological and biochemical parameters were in normal range before quetiapine treatment. Because our patient didn't use any other medication except quetiapine and other causes of hemolytic anemia were excluded with history, physical examination, clinical findings and laboratory tests, hemolytic anemia of patient was considered due to AlHA related with quetiapine use.

Drugs induced hemolysis may occur as immune-related or non-immune-related. Three main mechanisms were explained in drug-related immune hemolysis; First mechanism, which is also known as haptene, is a type of hemolysis due to absorption of drug into erythrocyte membrane and gain immunological features, thus antibodies against this complex causes hemodialysis. It is mostly extravascular, progresses slowly, rarely causes severe disease and regresses after discontinuation of drug. Second mechanism, which is also known as complex type, is a type of hemolysis caused by destruction of erythrocyte membrane with immunological and non-immunological paths after formation of a complex of antigens, which include drug and plasma proteins, and antibodies. Hemolysis is intravascular and usually ends 1-2 days after discontinuation of the drug. Third mechanism, which is also known as autoimmune type (alfametildopa), is a hemolysis caused due to immune response to erythrocyte antigens by drug (stimulated autoimmune). Hemolysis occur slowly with long-term use of drug and regresses slowly after discontinuation of the drug. ${ }^{1-3)}$ Hemolysis type of
AlHA in our patient might be considered as alpha methyldopa because of long-lasting erythrocyte destruction. In this type, drug should be discontinued when hemolysis is clinically apparent. Even though it usually takes a couple days to resolve, it might also last a few months. Laboratory tests and clinical findings of our patient improved at 21 st day of treatment however his direct coombs test turned negative at 145th day of treatment.

Hematological side effects usually occur at the start of the therapy. Our patient also had hematological side effects at the first week of quetiapine treatment. If drug-related hemolytic anemi as have mild clinical findings, discontinuation of the drug might be enough but in serious cases such as ours, it is important to initiate supportive treatment with corticosteroid therapy. ${ }^{2,3)}$ We used corticosteroids in line with supportive treatment in our case.

In conclusion, we believe quetiapine was responsible for erythrocyte destruction in our case. However, it is unclear whether quetiapine or its metabolites cause this clinical picture and whether hemolysis occurred with or without dose-dependent manner. To our knowledge, this case is the first case to report quetiapine-related AIHA and one should always keep in mind that atypical antipsychotics might cause several hematological side effects including hemolytic anemia. In addition, we present only a child patient of quetiapine-induced AlHA in this case report, therefore there is a need for further clinical studies to determine the relationship between atypical antipsychotics such as quetiapine and AlHA.

\section{REFERENCES}

1. Bass GF, Tuscano ET, Tuscano JM. Diagnosis and Classification of autoimmune hemolytic anemia. Autoimmun Rev 2014; 13:560-564.

2. Garratty G. Immune hemolytic anemia associated with drug therapy. Blood Rev 2010;24:143-150.

3. Ware RE. Autoimmune hemolytic anemia. In: Orkin $\mathrm{SH}$, Nathan DG, Ginsburg D, Look AT, Fisher D, Lux SE, editors. Nathan and Oski's Hematology of infancy and childhood. 7th Ed. Philadelphia:Saunders Elsevier;2009. p.613-658.

4. Erdoğan S. Hematological side effects of atypical antipsychotic drugs. Curr Approach Psychiatry 2009;1:255-279.

5. Flanagan RJ, Dunk L. Haematological toxicity of drugs used in psychiatry. Hum Psychopharmacol 2008;23 Suppl 1:27-41.

6. Oyesanmi O, Kunkel EJ, Monti DA, Field HL. Hematologic side effects of psychotropics. Psychosomatics 1999;40:414421.

7. Jovanović N, Lovretić V, Kuzman MR. The use of electro- 
convulsive therapy and general anaesthesia in catatonic schizophrenia complicated by clozapine-induced pancytopenia-case report. Psychiatr Danub 2014;26:285-287.

8. Iraqi A. A case report of pancytopenia with quetiapine use. Am J Geriatr Psychiatry 2003;11:694.

9. Huynh M, Chee K, Lau DH. Thrombotic thrombocytopenic purpura associated with quetiapine. Ann Pharmacother 2005; 39:1346-1348

10. Mathews M, Muzina DJ. Atypical antipsychotics: new drugs, new challenges. Cleve Clin J Med 2007;74:597-606.

11. Ruhé HG, Becker HE, Jessurun $\mathrm{P}$, Marees $\mathrm{CH}$, Heeringa $M$,
Vermeulen HD. Agranulocytosis and granulocytopenia associated with quetiapine. Acta Psychiatr Scand 2001;104:311313; discussion 313-314.

12. Cowan C, Oakley C. Leukopenia and neutropenia induced by quetiapine. Prog Neuropsychopharmacol Biol Psychiatry 2007;31:292-294.

13. Arslan FC, Aykut DS, Ince C, Tiryaki A. Neutropenia and thrombocytopenia induced by quetiapine monotherapy: a case report and review of literature. Bull Clin Psychopharmacol 2016;26:319-323. 